\title{
Angiogenic effects of apigenin on endothelial cells after hypoxia-reoxygenation via the caveolin-1 pathway
}

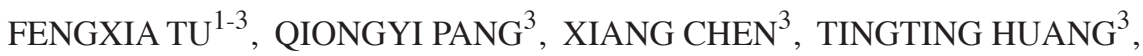 \\ MEIXIA LIU ${ }^{3}$ and QIONGXIANG ZHAI ${ }^{1,2}$ \\ ${ }^{1}$ Southern Medical University, Guangzhou, Guangdong 510515; ${ }^{2}$ Department of Pediatrics, Guangdong General Hospital, \\ Guangdong Academy of Medical Sciences, Guangzhou, Guangdong 510080; ${ }^{3}$ Department of Pediatrics, \\ Second Affiliated Hospital and Yuying Children's Hospital of Wenzhou Medical University, \\ Wenzhou, Zhejiang 325000, P.R. China
}

Received November 3, 2016; Accepted September 12, 2017

DOI: 10.3892/ijmm.2017.3159

\begin{abstract}
In the present study, we aimed to elucidate whether apigenin contributes to the induction of angiogenesis and the related mechanisms in cell hypoxia-reoxygenation injury. The role of apigenin was examined in human umbilical vein endothelial cell (HUVEC) viability, migration and tube formation in vitro. To investigate the related mechanisms, we used caveolin-1 short interfering RNA. The viability of HUVECs was measured using Cell Counting Kit- 8 assays, HUVEC migration was analyzed by crystal violet staining, and a tube formation assay was performed using the branch point method. Expression of caveolin-1, vascular endothelial growth factor (VEGF), and endothelial nitric oxide synthase (eNOS) in HUVECs was examined by polymerase chain reaction and western blotting. Our data revealed that apigenin induced angiogenesis in vitro by increasing the tube formation ability of HUVECs, which was counteracted by caveolin-1 silencing. Compared to the NC group, Caveolin-1 and eNOS expression was upregulated by apigenin, whereas compared to the NC group, eNOS expression was increased upon caveolin-1 silencing. The expression of VEGF was increased by treatment with apigenin; however, compared to the NC group, caveolin-1 silencing did not affect VEGF expression, and apigenin did not increase VEGF expression in HUVECs after caveolin-1 silencing. These data suggest that apigenin may be a candidate
\end{abstract}

Correspondence to: Dr Qiongxiang Zhai, Department of Pediatrics, Guangdong General Hospital, Guangdong Academy of Medical Sciences, 106 Zhongshan Second Road, Guangzhou, Guangdong 510080, P.R. China

E-mail: qiongxiangzhai@163.com

Abbreviations: HUVECs, human umbilical vein endothelial cells; HR, hypoxia-reoxygenation; VEGF, vascular endothelial growth factor; NO, nitric oxide; eNOS, endothelial nitric oxide synthase

Key words: apigenin, caveolin-1, vascular endothelial growth factor, endothelial nitric oxide synthase, hypoxia-reoxygenation, human umbilical vein endothelial cells therapeutic target for stroke recovery by promoting angiogenesis via the caveolin-1 signaling pathway.

\section{Introduction}

Recent studies have suggested that angiogenesis in the ischemic penumbra area may play a crucial role in neural protection and tissue recovery. Angiogenesis is an important structural adaptation to increase vascular perfusion, sprouting, cell proliferation, migration and maturation $(1,2)$. Numerous regulatory angiogenic factors have been identified, and their molecular modulations are associated with several angiogenic disorders $(3,4)$. Vascular endothelial growth factor (VEGF) and nitric oxide (NO) from activated endothelial nitric oxide synthase (eNOS) are key regulators of normal and pathological angiogenesis $(5,6)$. The survey and development of new agents, which promote angiogenesis via growth factors, have become a focus of therapeutic strategies for ischemic diseases (7).

Caveolin-1, a coat protein of caveolae, is involved in many signaling pathways and functions of endothelial cells $(8,9)$. The caveolin-1 signaling pathway is widely known for its role in regulating cellular functions, including signal transduction, endocytosis, transcytosis, molecular transport, embryonic vessel development, normal tissue growth, and wound healing, as well as pathological processes such as ischemia and tumor growth $(10,11)$. The importance of caveolin-1 has been confirmed in endothelial cells during angiogenesis. Gao et al (12) found that caveolin-1 and VEGF expression induced by treadmill exercise after middle cerebral artery occlusion was consistent with the good neurological outcomes of decreased infarct volumes and increased microvessel densities. In addition, the expression of VEGF could be significantly inhibited by a caveolin-1 inhibitor. Caveolin-1 overexpression has been reported to enhance endothelial capillary tubule formation (13). Despite a number of studies on the involvement of caveolin-1 in VEGF-stimulated angiogenesis, whether caveolin-1 is a stimulator or inhibitor of angiogenesis is still controversial. Thus, further studies are needed to identify the mechanism by which caveolin-1 regulates VEGF. eNOS localized to the inner leaflet of caveolar membranes and in the Golgi of endothelial cells is believed to be maintained in an inactive state owing to a direct interaction 
with caveolin-1 $(14,15)$. It has been documented that decreasing the association of caveolin-1 with eNOS results in activation of eNOS $(16,17)$. However, the mechanism of caveolin-1-mediated inhibition of eNOS activation is unclear. Regulation of eNOS by caveolin-1 is an important physiological mechanism to control vascular reactivity.

Apigenin is a naturally occurring flavonoid that has a variety of pharmacological activities, mainly including antitumor, anti-oxidative stress, and anti-DNA damage activities (18). Furthermore, apigenin has vasorelaxing and anti-platelet properties that may reduce the risk of coronary heart disease and improve endothelial functions (19-21). Even though apigenin has potential effects on both endothelial cells and neurons, it is unclear whether there is an effect on the promotion of angiogenesis and the underlying mechanisms. Nevertheless, recent data have indicated that apigenin inhibits VEGF expression and tumor angiogenesis $(22,23)$. However, normal cells and cancer cells have different characteristics, and the potential effects of apigenin on the expression of VEGF have not been clarified in a normal biological system. We previously demonstrated that treatment of rats with apigenin after stroke enhanced the expression of both VEGF and caveolin-1 at the brain-infarct border zone, and that caveolin-1 expression correlates with improved functional recovery $(24,25)$. However, we have not further explored the angiogenic effect of apigenin.

These findings suggest that caveolin-1 may also be involved in apigenin-induced angiogenesis after hypoxiareoxygenation (HR) of human umbilical vein endothelial cells (HUVECs). To test this hypothesis and explore the mechanisms involved in apigenin-induced angiogenesis, we determined the effects of apigenin on the caveolin-1-dependent signaling pathway upon caveolin-1 silencing, as well as the expression of VEGF and eNOS in vitro. This study may provide the basis for the novel therapeutic management of stroke by angiogenesis.

\section{Materials and methods}

Chemicals, reagents and culture medium. Apigenin $(\geq 99 \%$ pure) was purchased from Sigma-Aldrich (St. Louis, MO, USA). It was diluted in dimethyl sulfoxide purchased from Sigma-Aldrich at a final concentration of $40 \mathrm{mM}$. HUVECs were purchased from the Cell Bank of the Chinese Academy of Sciences. Dulbecco's modified Eagle's medium (DMEM) was purchased from Gibco (Thermo Fisher Scientific, Waltham, MA, USA). Fetal bovine serum (FBS) was purchased from Biosun Biotech (Shanghai, China). Phosphate-buffered saline was purchased from Yuanpei (Shanghai, China). Trypsin was purchased from Boguang Biotech (Shanghai, China). Trizol was purchased from Takara Bio (Dalian, China). Glutamine was purchased from Amresco (Solon, OH, USA). Reverse transcriptase was purchased from Fermentas China (Shanghai, China). Anti-caveolin-1 (ab2910) and -eNOS (ab199956) antibodies were obtained from Abcam (Cambridge, MA, USA). An anti-VEGF antibody (sc-1876) was obtained from Santa Cruz Biotechnology, Inc. (Santa Cruz, CA, USA). SYBR-Green Mix was purchased from Dongsheng Biotech (Guangzhou, China). Transwells were purchased from Corning, Inc. (Corning, NY, USA). Crystal violet was purchased from Genmed Scientifics Inc. (Shanghai, China).
Cell culture and HR injury. HUVECs were cultured in DMEM containing $10 \% \mathrm{FBS}, 1 \%$ penicillin/streptomycin and $1 \%$ glutamine. For exposure to hypoxia, the HUVECs were incubated in $1 \% \mathrm{O}_{2}$ plus $5 \% \mathrm{CO}_{2}$ balanced with $\mathrm{N}_{2}$ for 0,2 and $6 \mathrm{~h}$. Following exposur to hypoxia, the cells were returned to a standard incubator with the normoxic condition of humidified air with $5 \% \mathrm{CO}_{2}$ for 24 and $48 \mathrm{~h}$. Zero hours was defined as the onset after cells were exposed to hypoxia.

Cell viability assay. Cell viability was measured by the Cell Counting Kit-8 (CCK-8) assay (Dojindo Laboratories, Kumamoto, Japan) as described previously (26). Briefly, HUVECs were subcultured in a 96 -well plate at $5 \times 10^{3}$ cells/well in DMEM. Then, the cells were treated with increasing concentrations of apigenin $(10,20,50$ and $80 \mu \mathrm{M})$. After hypoxia for $6 \mathrm{~h}$ and oxygenation for $24 \mathrm{~h}, 10 \mu \mathrm{l}$ CCK-8 solution was added to each well. After incubation for $2 \mathrm{~h}$ at $37^{\circ} \mathrm{C}$ in the dark, the absorbance was measured at $450 \mathrm{~nm}$ using a Multiskan MK3 microplate reader (Thermo Labsystems, Paris, France). Cells cultured in serum-free DMEM were used as a background control. The absorbance for each apigenin concentration alone in serum-free DMEM and CCK-8 solution was also measured at $450 \mathrm{~nm}$. The appropriate concentration was chosen for the following experiment. The cell viabilities of four groups (NC, $\mathrm{NC}+$ apigenin, caveolin-1-KD and caveolin-1-KD + apigenin) were tested at 1, 2, 3, 4, 5 and 6 days after treatment with apigenin, caveolin-1 short interfering RNA (siRNA), or negative control siRNA. The NC group was the negative control group. The NC + apigenin group was the negative control treated with apigenin. The caveolin-1-KD group was subjected to caveolin-1 silencing. The caveolin-1-KD + apigenin group was subjected to caveolin-1 silencing and treatment with apigenin. Cell viability was calculated using the following formula: cell viability (\%) $=\left(\mathrm{OD}_{\text {sample }}-\mathrm{OD}_{\text {background }}\right) /\left(\mathrm{OD}_{\text {control }}-\mathrm{OD}_{\text {background }}\right) \times 100 \%$, where $\mathrm{OD}_{\text {control }}$ and $\mathrm{OD}_{\text {sample }}$ are the optical density (OD) of the negative control and apigenin-treated groups, respectively. The absorbance was directly correlated with the number of metabolically active HUVECs. All conditions were measured in at least three independent experiments. Data analysis was performed in a blinded manner.

Caveolin-1 siRNA generation and transduction. Caveolin-1 was silenced in the HUVECs by lentiviral siRNA transfection. The lentiviral vectors for caveolin-1 and control siRNAs were obtained from R\&S Biotechnology Co., Ltd. (Shanghai China). Briefly, caveolin-1 was amplified and subcloned into the pcDNA6.2 vector with the enhanced green fluorescent protein (EGFP) gene, and then EGFP-caveolin-1 was cloned into the pLenti6.3-MCS/V5 DEST vector. The resulting plasmid was analyzed and verified by gel electrophoresis and sequencing. To obtain lentiviruses, 293T cells were co-transfected with caveolin-1 or control siRNA lentivirus expression plasmids and a packaging plasmid mix (Invitrogen; Thermo Fisher Scientific Inc.) using POLOdeliverer ${ }^{\mathrm{TM}} 3000$ transfection reagent (Ruisai Inc., Shanghai, China) according to the instructions provided by the manufacturer. Following lentivirus infection for $48 \mathrm{~h}$, HUVECs transduced with fluorescently tagged proteins were selected and verified by fluorescence microscopy. The cells were applied to the following experiments. 
Transwell migration assay. The bottom chambers of Transwells were filled with DMEM and the top chambers were seeded with HUVECs transfected with siRNA for $72 \mathrm{~h}$ and then treated with $10 \mu \mathrm{M}$ apigenin, hypoxia for $6 \mathrm{~h}$, and reoxygenation $24 \mathrm{~h}$. Cells on the top surface of the membrane (non-migrated cells) were removed with a cotton swab, and cells that had migrated onto the bottom sides of the membrane were fixed in $4 \%$ paraformaldehyde and stained with $2 \%$ crystal violet. The absorbance was measured at $570 \mathrm{~nm}$ using a Multiskan MK3 microplate reader. The OD value indicated the number of migrated cells. Each experiment was performed in triplicate. All data analysis was performed in a blinded manner.

Tube formation assay. An endothelial cell tube formation assay is a useful indicator of angiogenesis potential. In the present study, the tube formation assay was performed using the branch point method (27). In brief, HUVECs (5x10 /well) were seeded onto a 96-well plate pre-coated with Matrigel (50 $\mu \mathrm{l})$ and cultured at $37^{\circ} \mathrm{C}$ in a $5 \% \mathrm{CO}_{2}$ incubator. The formed network of tubes was visualized at x100 magnification by light microscopy. The number of branch points was counted to calculate the branch point density. Each experiment was performed in triplicate. All data analysis was performed in a blinded manner.

Quantitative polymerase chain reaction ( $q P C R$ ) analysis of caveolin-1. Gene expression was measured by qPCR in endothelial cells harvested after treatments. qPCR was performed to investigate the expression of caveolin-1. Total RNA was isolated and purified using TRIzol $^{\circledR}$ Plus RNA purification kit (Takara Bio), according to the manufacturer's instructions. RNA was reverse transcribed into cDNA that was utilized as a template in the subsequent qPCR amplifications using a SYBRGreen Mix kit (Dongsheng Biotech). The qPCR primers included:caveolin-1 (forward,CGCAGGGACATCTCTACACC and reverse, CTTCCAAATGCCGTCAAAAC, 233 bp). Each experiment was repeated at least three times.

Western blot analysis of caveolin-1, VEGF and eNOS levels. Cells subjected to various treatments were lysed in lysis buffer. Equal amounts of total proteins were separated on sodium dodecyl sulfate polyacrylamide gels (caveolin-1, 12\%; VEGF, 10\%; eNOS, $8 \%$ ) and then electrophoretically transferred to a polyvinylidene difluoride membrane. The membrane was blocked with $5 \%$ dry skim milk for $1 \mathrm{~h}$, incubated with anti-caveolin-1 (1:800), anti-VEGF (1:200), and anti-eNOS (1:500) antibodies at $4^{\circ} \mathrm{C}$ overnight, and then incubated with HRP-labeled goat anti-rabbit antibody (1:3,000; A0208, Beyotime Biotech, Jiangsu, China) for $1 \mathrm{~h}$. Labeled proteins were detected using an enhanced chemiluminescence detection kit. The relative quantity of proteins was analyzed using Quantity One software and normalized to the loading control. Each experiment was repeated at least three times.

Statistical analyses. Data are presented as the mean \pm standard error of the mean (SEM). The results were analyzed by SPSS 20.0 software (SPSS Inc. Chicago, IL, USA). Mean values were derived from at least three independent experiments. Statistical comparisons between experimental groups were performed by one-way analysis of variance. The level of statistical significance was set at $\mathrm{P}<0.05$.

\section{Results}

Determination of optimal durations for HR. To determine appropriate durations for HR, HUVECs were subjected to HR for various times, and then expression of caveolin-1, VEGF and eNOS was assessed by qPCR and western blotting. The results showed that the mRNA expression levels of caveolin-1, VEGF, and eNOS at $6 \mathrm{~h}$ of hypoxia were lower than those at $0 \mathrm{~h}$. After $48 \mathrm{~h}$ of reoxygenation, the mRNA expression of caveolin-1, VEGF, and eNOS was recovered for any duration of hypoxia (Fig. 1A). The protein expression of caveolin-1 declined slightly, but the expression of VEGF and eNOS increased during hypoxia for $6 \mathrm{~h}$ and reoxygenation for $24 \mathrm{~h}$, indicating that the protein expression was not consistent with the mRNA expression. After $48 \mathrm{~h}$ of reoxygenation for any duration of hypoxia, expression was restored for all three proteins (Fig. 1B). Cell viability was markedly decreased and cell necrosis was increased by hypoxia for $6 \mathrm{~h}$ and reoxygenation for $24 \mathrm{~h}$ (Fig. 1C). Considering these results, we induced hypoxia for $6 \mathrm{~h}$ and reoxygenation for $24 \mathrm{~h}$ in further experiments.

Determination of the appropriate concentration of apigenin. To ascertain the appropriate non-toxic concentration of apigenin for the treatment of HUVECs, the effect of apigenin on HUVEC viability was examined by CCK-8 assays. The results showed that 10 and $20 \mu \mathrm{M}$ apigenin had protective effects on HUVECs after HR, while apigenin reduced cell viability at concentrations $\geq 50$ (Fig. 2). The viability of HUVECs treated with $10 \mu \mathrm{M}$ apigenin was higher than that of HUVECs treated with $20 \mu \mathrm{M}$ apigenin. Therefore, we chose $10 \mu \mathrm{M}$ as the appropriate concentration of apigenin for the following experiments.

Transfection of caveolin-1 siRNA into HUVECs. Cells were transfected with caveolin-1 or control siRNAs for $72 \mathrm{~h}$. EGFP-positive cells were observed by fluorescence microscopy. The positive cells (Fig. 3) showed that the HUVECs were successfully transfected with the siRNA vectors.

Effects of apigenin on caveolin-1-induced angiogenesis of HUVECs after HR. Cell viability, migration and tube formation were analyzed as indicators of angiogenesis. To investigate the effects of apigenin on HUVEC viability, we performed CCK-8 assays. We found that cell viability was markedly decreased after HR. However, apigenin did not promote the viability of HUVECs reoxygenated for more than 3 days (Fig. 4A). HUVEC viability was increased by treatment with apigenin (Fig. 4B). Caveolin-1 silencing inhibited the viability of HUVECs, and apigenin recovered their viability (Fig. 4B).

Migration of endothelial cells plays a key role in angiogenesis. Therefore, we determined the effects of apigenin on HUVEC migration after HR (Fig. 5). We found that apigenin promoted the migration of HUVECs. Caveolin-1 siRNA suppressed the HUVEC migration. However, the inhibition of HUVEC migration was reversed following treatment with apigenin.

To evaluate the role of apigenin in regulating angiogenesis, we next assessed the effects of apigenin on tube formation of HUVECs. As expected, apigenin promoted tube formation after HR. To verify the involvement of caveolin-1 in the process 

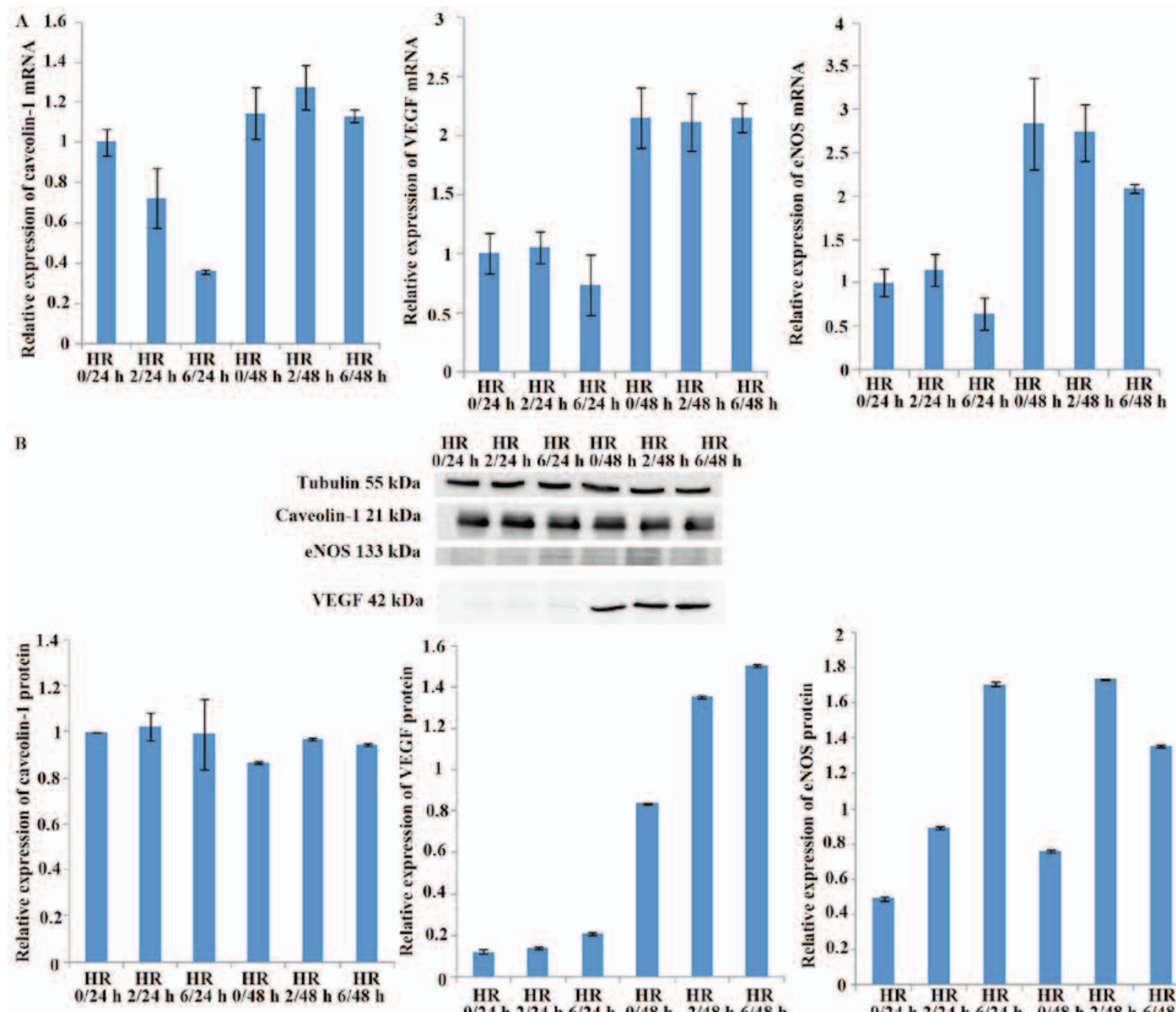

$0 / 24$ h $2 / 24$ h $6 / 24$ h $0 / 48$ h $2 / 48$ h $6 / 48$ h
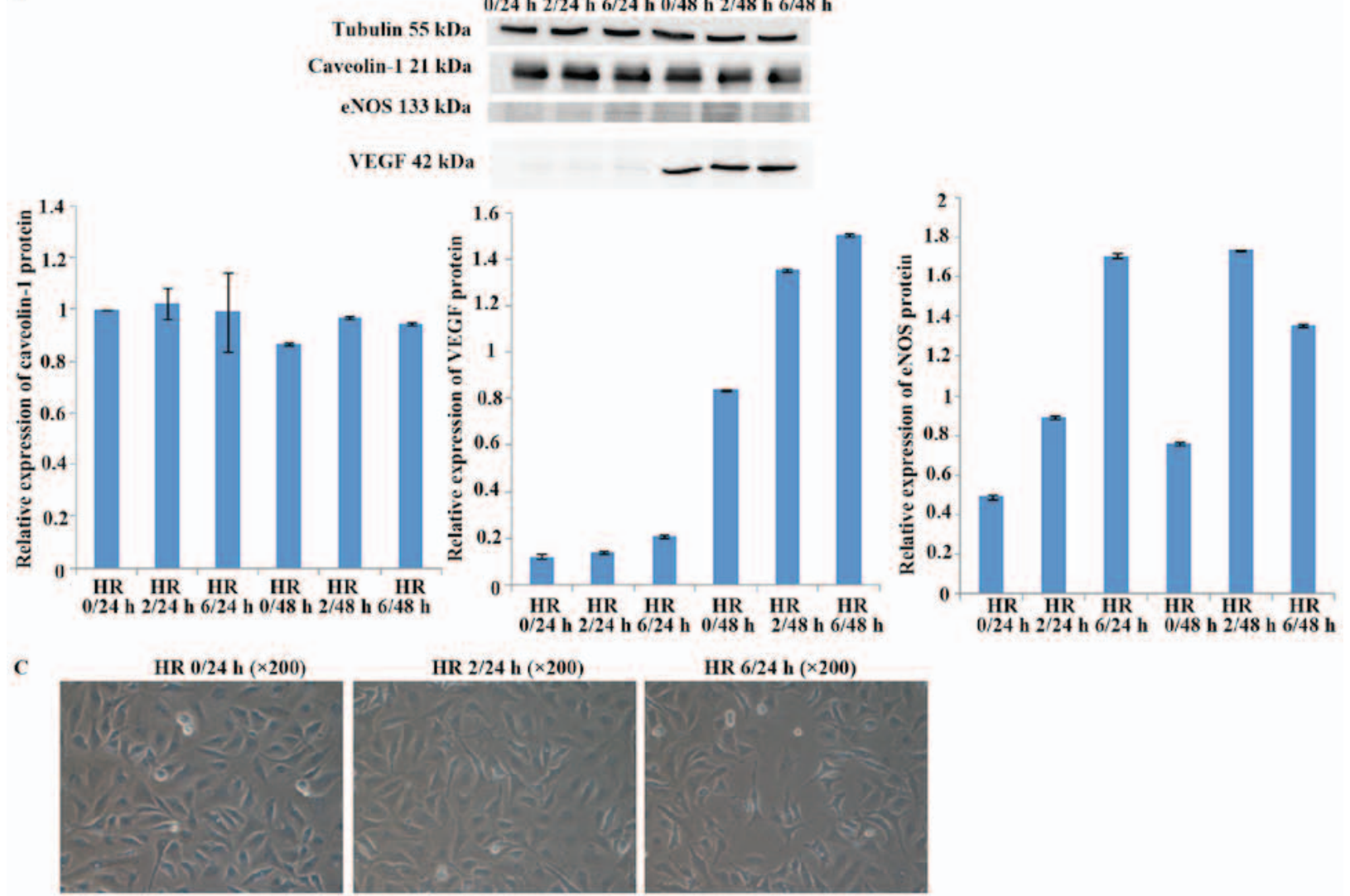

HR 2/24h $(\times 200)$

HR $6 / 24$ h $(\times 200)$
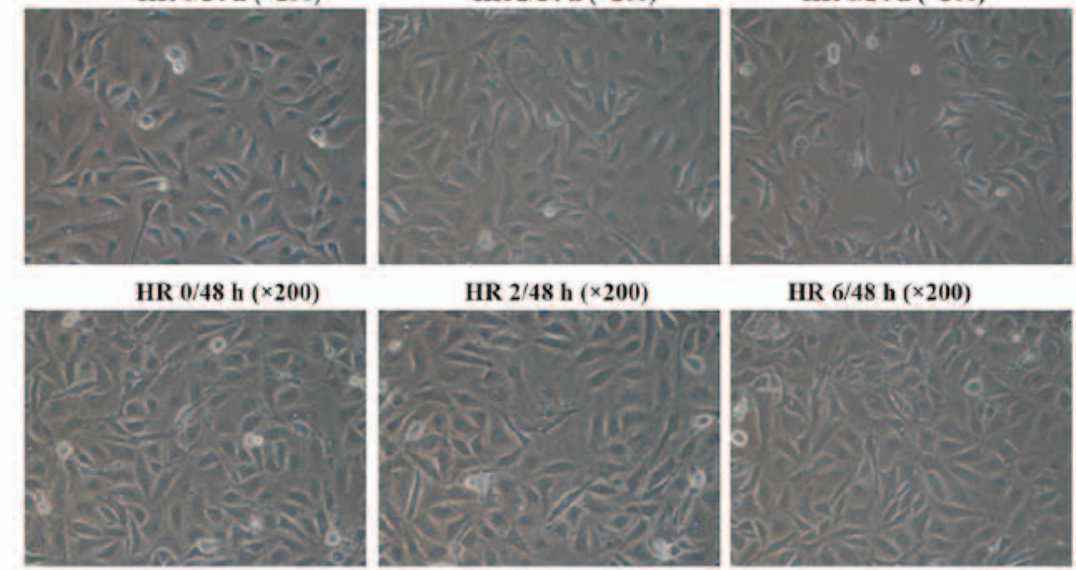

HR 6/48 h ( $\times 200)$

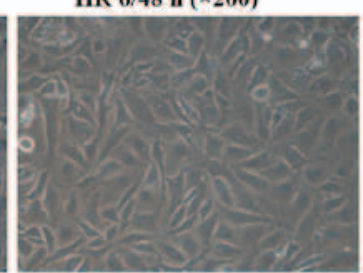

Figure 1. Expression of caveolin-1, vascular endothelial growth factor (VEGF), and endothelial nitric oxide synthase (eNOS) in human umbilical vein endothelial cells (HUVECs) after various durations of hypoxia-reoxygenation (HR). Cells were incubated under hypoxic conditions $\left(1 \% \mathrm{O}_{2}\right.$ ) for 0,2 or $6 \mathrm{~h}$ and then reoxygenated for 24 or $48 \mathrm{~h}$. (A) RT-PCR analysis of caveolin-1, VEGF and eNOS in HUVECs. mRNA expression of caveolin-1, VEGF and eNOS was decreased after hypoxia for $6 \mathrm{~h}$ and reoxygenation for $24 \mathrm{~h}$. The mRNA expression of caveolin-1, VEGF and eNOS was restored after reoxygenation for $48 \mathrm{~h}$ compared with reoxygenation for $24 \mathrm{~h}$. (B) Western blot analysis of caveolin-1, VEGF and eNOS in HUVECs. The protein expression of caveolin-1 was decreased slightly, while VEGF and eNOS protein expression was increased after hypoxia for $6 \mathrm{~h}$ and reoxygenation for $24 \mathrm{~h}$. However, compared with reoxygenation for $24 \mathrm{~h}$, VEGF and eNOS protein expression was recovered after reoxygenation for $48 \mathrm{~h}$. (C) Cell viability at various durations of HR. The example shown is representative of six independent experiments. The cell viability was markedly decreased and cell necrosis was increased by hypoxia for $6 \mathrm{~h}$ and reoxygenation for $24 \mathrm{~h}$.

of tube formation, we used RNA interference to selectively silence caveolin-1. The tube formation was decreased after caveolin-1 silencing. Apigenin had no effect on tube formation inhibited by caveolin-1 silencing (Fig. 6). 

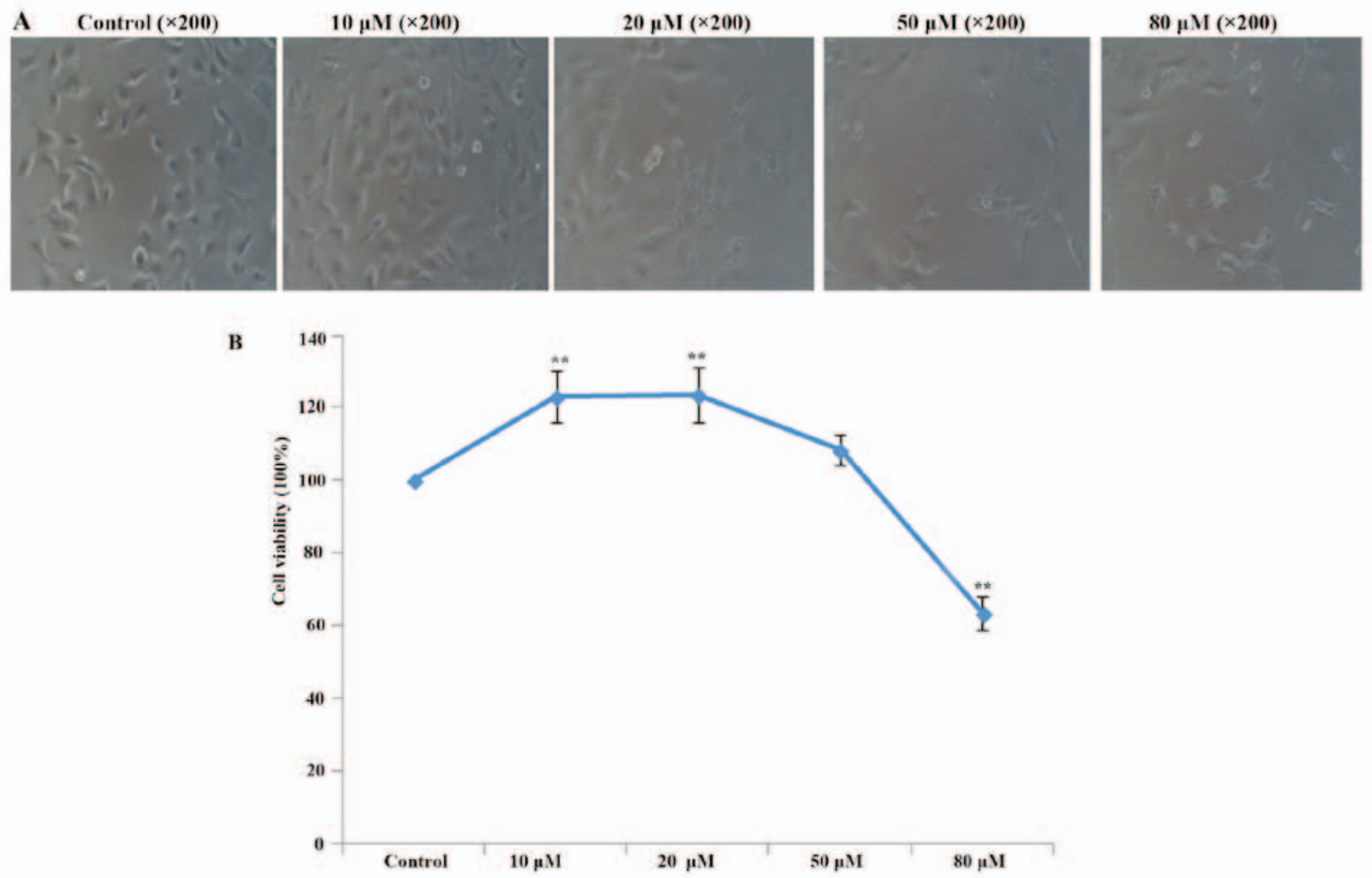

Figure 2. Effects of apigenin on human umbilical vein endothelial cell (HUVEC) viability after hypoxia-reoxygenation (HR). Cell viability is presented as a percentage of the control (untreated cells). (A) The status of HUVECs after treatment with $10 \mu \mathrm{M}$ apigenin was better than that after treatment with $20 \mu \mathrm{M}$ apigenin. The cells were necrotic after treatment with 50 and $80 \mu \mathrm{M}$ apigenin. (B) HUVEC viability after HR and treatment with various concentrations of apigenin. CCK-8 assay results showed that 10 and $20 \mu \mathrm{M}$ apigenin had protective effects on HUVECs after HR. However, cell damage was induced at $\geq 50 \mu \mathrm{M}$ apigenin. ${ }^{* *} \mathrm{P}<0.01$ vs. control group.

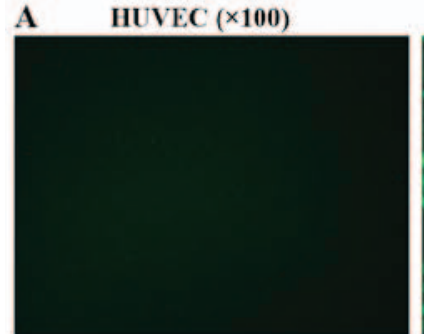

B

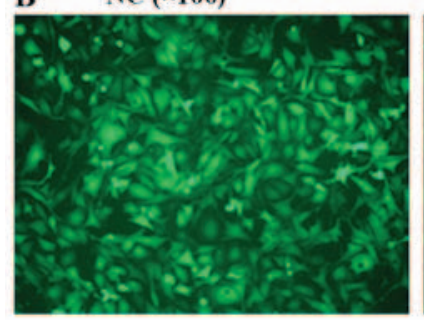

HUVEC-Caveolin-1-KD $(\times 100)$

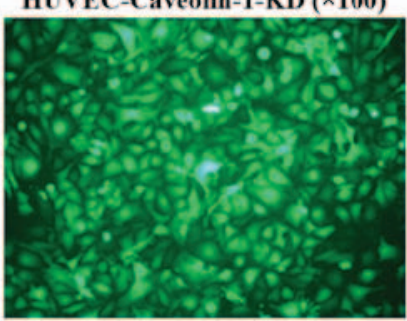

$\mathrm{NC}+$ Apigenin $(\times 100)$

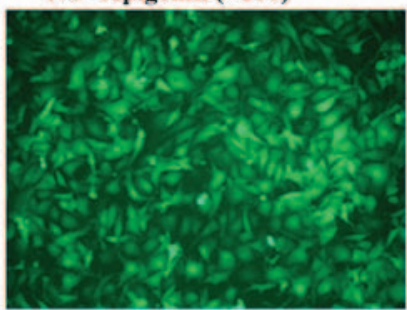

HUVEC-NC( $\times 100)$

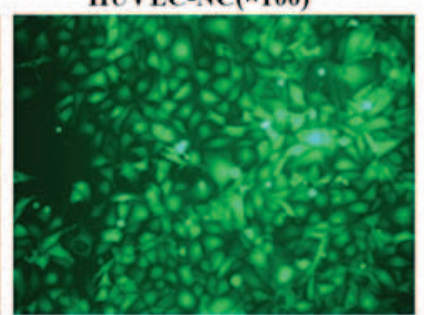

Caveolin-1-KD $(\times 100)$

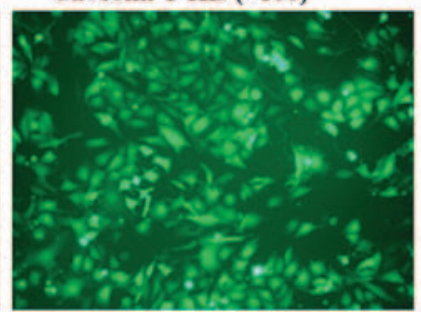

Caveolin-1-KD+Apigenin $(\times 100)$

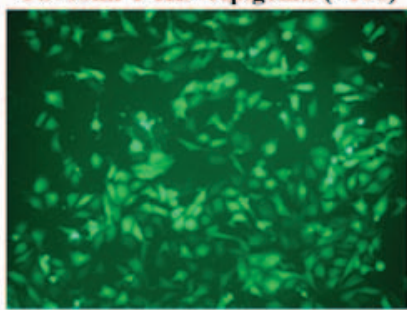

Figure 3. Human umbilical vein endothelial cell (HUVEC) transfection with caveolin-1 short interfering RNA (siRNA). Cells were transfected with a specific caveolin-1 siRNA or control siRNA for $72 \mathrm{~h}$, followed by treatment with apigenin $(10 \mu \mathrm{M})$ or solvent (dimethyl sulfoxide), and then subjected to hypoxia for $6 \mathrm{~h}$ and reoxygenation for $24 \mathrm{~h}$. Enhanced green fluorescent protein (EGFP)-positive cells were observed by fluorescence microscopy at x100 magnification. (A) Cells transfected with specific caveolin-1 siRNA or control siRNA. (B) The EGFP-positive cells are shown in four different groups: NC group (normal conditions), caveolin-1-KD group (transfection with caveolin-1 siRNA), NC + apigenin group (transfection with negative control siRNA + treatment with apigenin), and caveolin-1-KD + apigenin group (transfection with caveolin-1 siRNA + treatment with apigenin).

Effects of apigenin on caveolin-1 levels in HUVECs. Caveolin-1 expression levels were evaluated by western blotting and qPCR. Apigenin did not affect caveolin-1 mRNA expression (Fig. 7A), but it increased caveolin-1 protein 

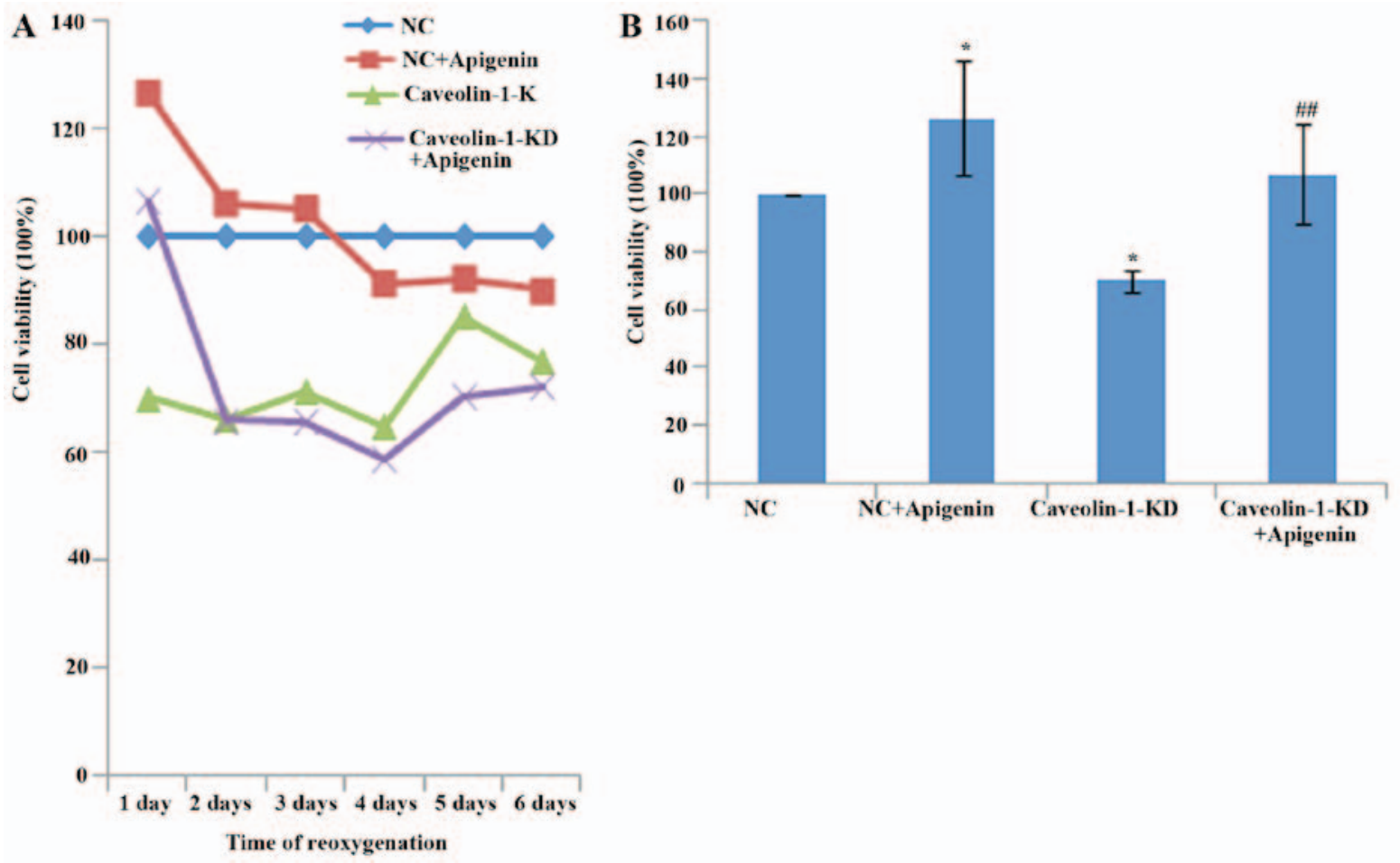

Figure 4. Effect of apigenin and caveolin-1 silencing on human umbilical vein endothelial cell (HUVEC) viability after hypoxia-reoxygenation (HR). Cells were analyzed after hypoxia for $6 \mathrm{~h}$ and reoxygenation for $24 \mathrm{~h}$ under three conditions: normal conditions (NC group), transfection of caveolin-1 short interfering RNA (siRNA) (caveolin-1-KD group), and treatment with apigenin (NC + Apigenin and caveolin-1-KD + apigenin groups). (A and B) Cell viability was measured by Cell Counting Kit-8 (CCK-8) assays. Values are the mean \pm SEM of three experiments $(n=3)$. ${ }^{*} \mathrm{P}<0.05$ vs. NC group; ${ }^{\# \#} \mathrm{P}<0.01$ vs. caveolin1-KD group.

A NC

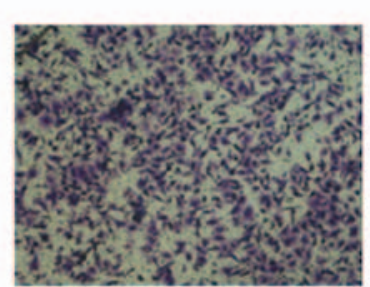

NC+Apigenin

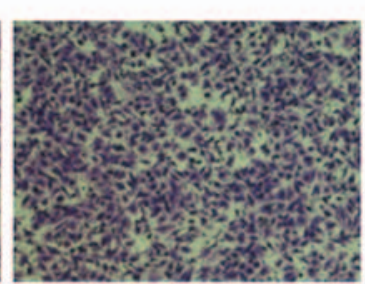

Caveolin-1-KD

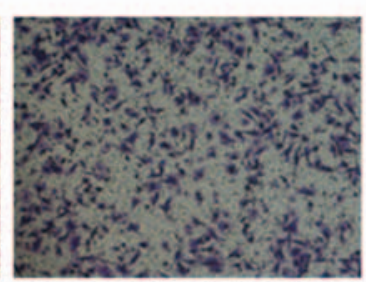

Caveolin-1-KD + Apigenin

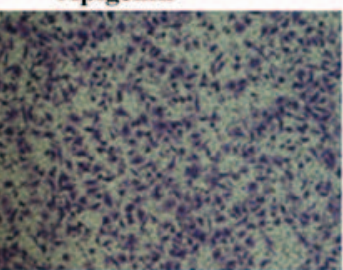

B

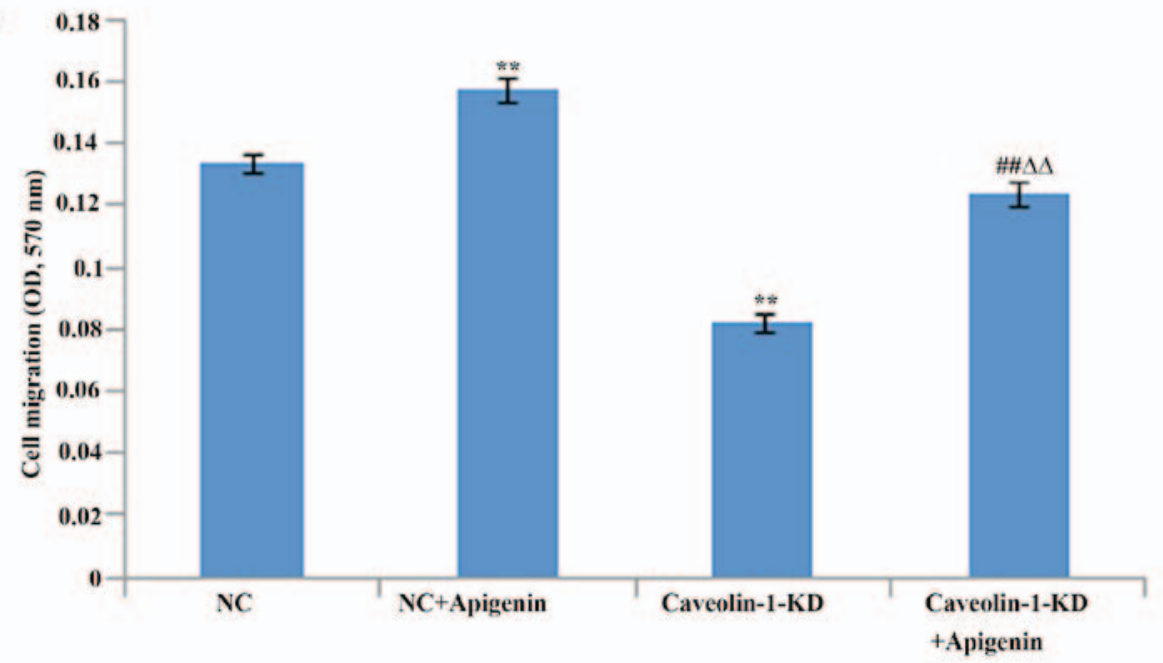

Figure 5. Effect of apigenin and caveolin-1 silencing on human umbilical vein endothelial cell (HUVEC) migration after hypoxia-reoxygenation (HR). Cells were analyzed after hypoxia for $6 \mathrm{~h}$ and reoxygenation for $24 \mathrm{~h}$ under three conditions: normal conditions (NC group), transfection of caveolin-1 short interfering RNA (siRNA) (caveolin-1-KD group), and treatment with apigenin (NC + apigenin and caveolin-1-KD + apigenin groups). (A) Migration was assessed by crystal violet staining (magnification, $x 100$ ). (B) The OD was measured by a microplate reader indicating the number of migrated cells. All values are presented as the mean \pm SEM of three experiments $(n=3) .{ }^{* *} \mathrm{P}<0.01$ vs. $\mathrm{NC}$ group; ${ }^{\# /} \mathrm{P}<0.01$ vs. caveolin-1-KD group; ${ }^{\Delta \Lambda} \mathrm{P}<0.01 \mathrm{vs}$. NC + apigenin group. 
A
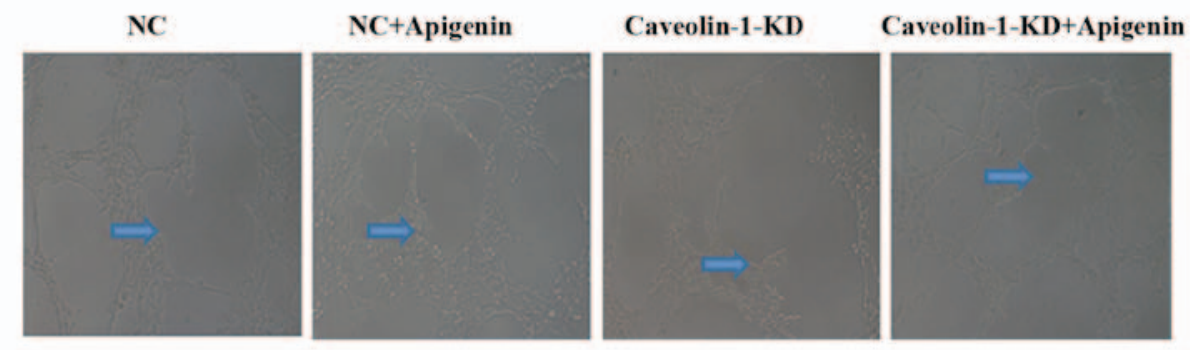

B

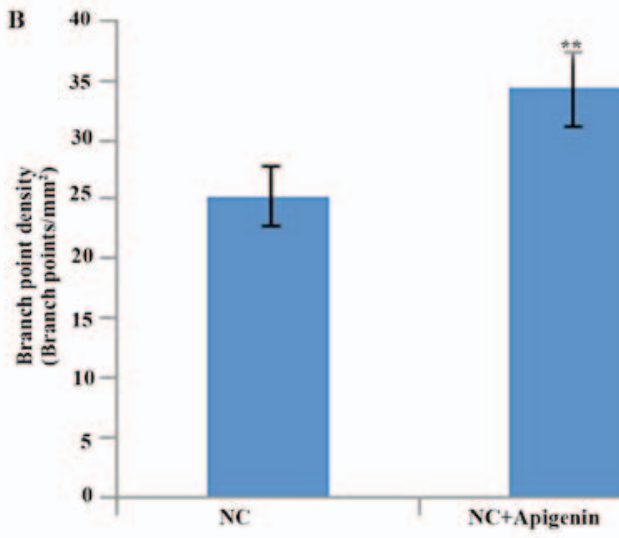

Figure 6. Effect of apigenin and caveolin-1 silencing on tube formation of human umbilical vein endothelial cells (HUVECs) after hypoxia-reoxygenation (HR). Cells were analyzed after hypoxia for $6 \mathrm{~h}$ and reoxygenation for $24 \mathrm{~h}$ under three conditions: normal conditions (NC group), transfection of caveolin-1 short interfering RNA (siRNA) (caveolin-1-KD group), and treatment with apigenin (NC + apigenin and caveolin-1-KD + apigenin groups). (A) Representative light microscopy images of tube formation were obtained after treatment with apigenin and caveolin-1 siRNA. Arrows indicate new tube formation. (B) The tube formation assay was performed by counting branch points. All values are presented as the mean \pm SEM of three experiments ( $=3$ ). ${ }^{* *} \mathrm{P}<0.01$ vs. NC group; ${ }^{\Delta \Delta} \mathrm{P}<0.01$ vs. $\mathrm{NC}+$ apigenin group.

expression in HUVECs after HR (Fig. 7B and C). To verify the effects of apigenin on caveolin-1 expression, we transfected the HUVECs with caveolin-1 siRNA. The results showed that caveolin-1 silencing inhibited the mRNA (Fig. 7A) and protein expression of caveolin-1 (Fig. 7B and C). Apigenin increased caveolin-1 protein expression after the transfection of HUVECs with caveolin-1 siRNA (Fig. 7B and C), but it did not upregulate the expression of caveolin-1 mRNA (Fig. 7A). These results indicated that apigenin may regulate translation and/or post-translational processing of caveolin-1 protein but not the transcription of caveolin-1 mRNA.

Effects of apigenin on VEGF levels in HUVECs. To examine the effect of apigenin on angiogenesis, we assessed the well-established pro-angiogenic mediator VEGF by western blot analysis. We found that apigenin promoted VEGF expression after HR. The results revealed that transfection with caveolin-1 siRNA did not significantly affect VEGF protein expression; apigenin increased VEGF expression, but it did not upregulate VEGF expression after caveolin-1 silencing (Fig. 7B and D).

Effects of apigenin on eNOS levels in HUVECs. Since eNOS also plays a critical role in angiogenesis and vascular permeability, we next examined the role of eNOS in apigenin-induced angiogenesis. Incubation of HUVECs with apigenin rapidly increased the protein expression of eNOS. Compared with the NC group, blocking the caveolin-1 pathway with caveolin-1 siRNA significantly increased the protein level of eNOS, whereas compared with the caveolin-1-KD group, apigenin downregulated the level of eNOS (Fig. 7B and E).

\section{Discussion}

Angiogenesis is involved in physiological processes, such as development, and pathological states such as stroke, cancer, and inflammatory diseases. Recent studies suggest that angiogenesis in the ischemic penumbra area may play a crucial role in neural protection and tissue recovery. Apigenin is orally bioavailable and non-toxic (28) and has potential effects on both endothelial and nerve cells. We previously showed that apigenin increases the expression of both VEGF and caveolin-1 at the brain-infarct border zone after stroke in rats, and that caveolin-1 expression correlates with improved functional recovery. However, we did not investigate the angiogenic effects of apigenin after stroke. Therefore, in the present study, we first investigated the angiogenic effects of apigenin on HUVECs after HR injury and the underlying mechanism. Caveolin-1 has attracted attention due to its contribution to angiogenesis. Caveolin-1 plays an important role in the mechanisms of cellular repair in many pathological conditions including stroke $(10,29)$. Previous studies, including our own, have demonstrated that ischemia/reperfusion increases caveolin-1 protein expression in association with increased microvessel density and better outcomes $(24,25,30)$. In the present study, we explored the involvement of caveolin-1 in the angiogenic effects of apigenin.

For this purpose, we examined the effects of apigenin on the viability, migration and tube formation of HUVECs after HR. 


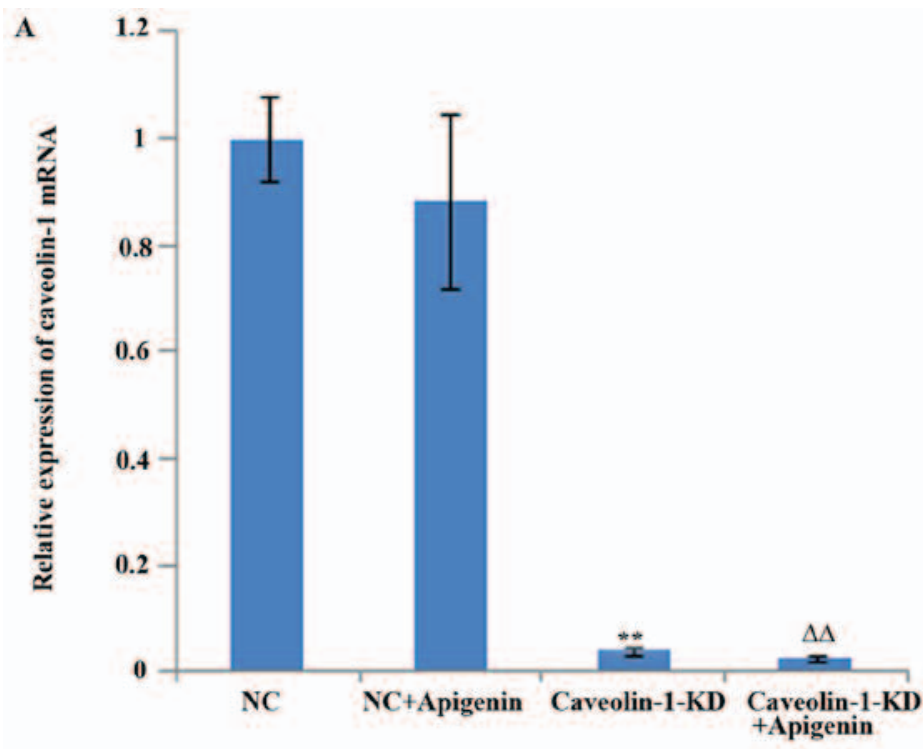

B
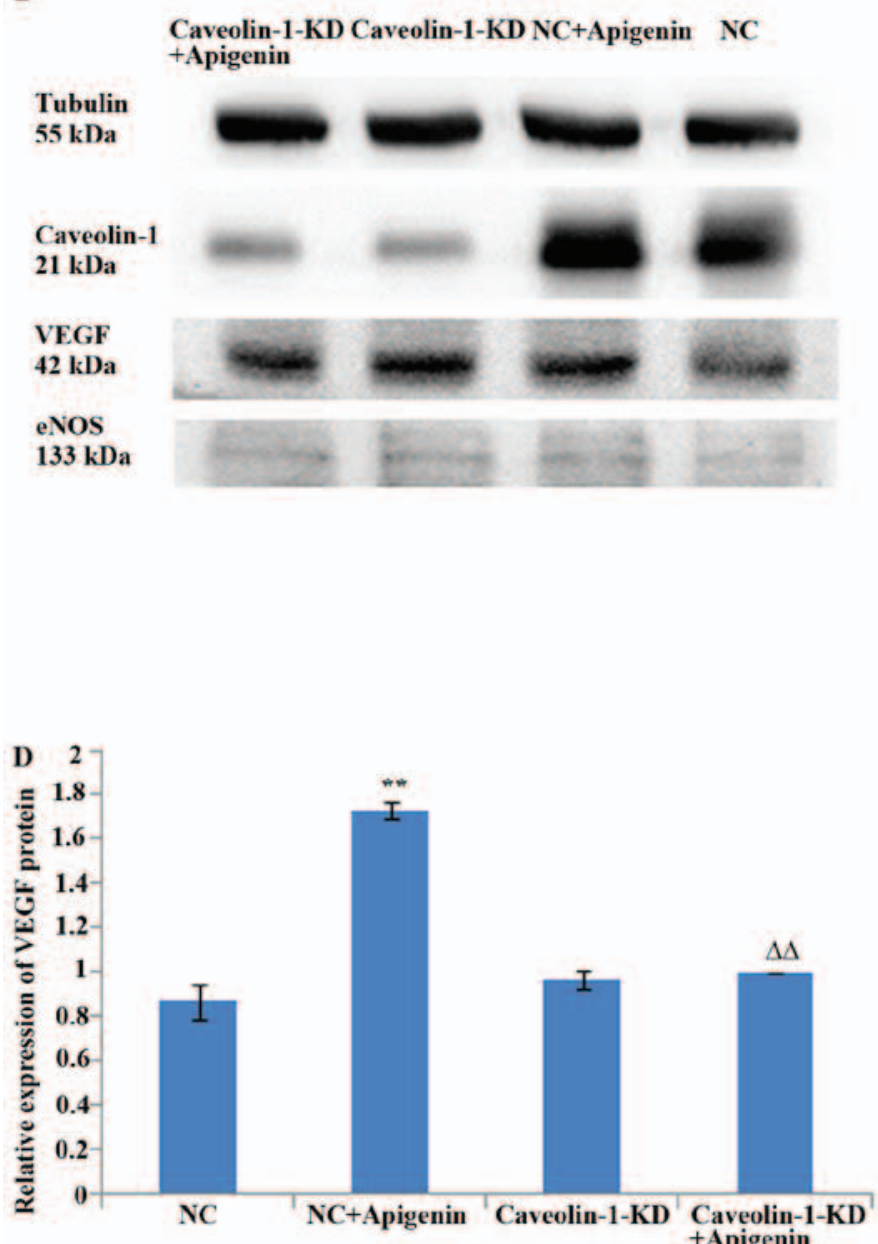
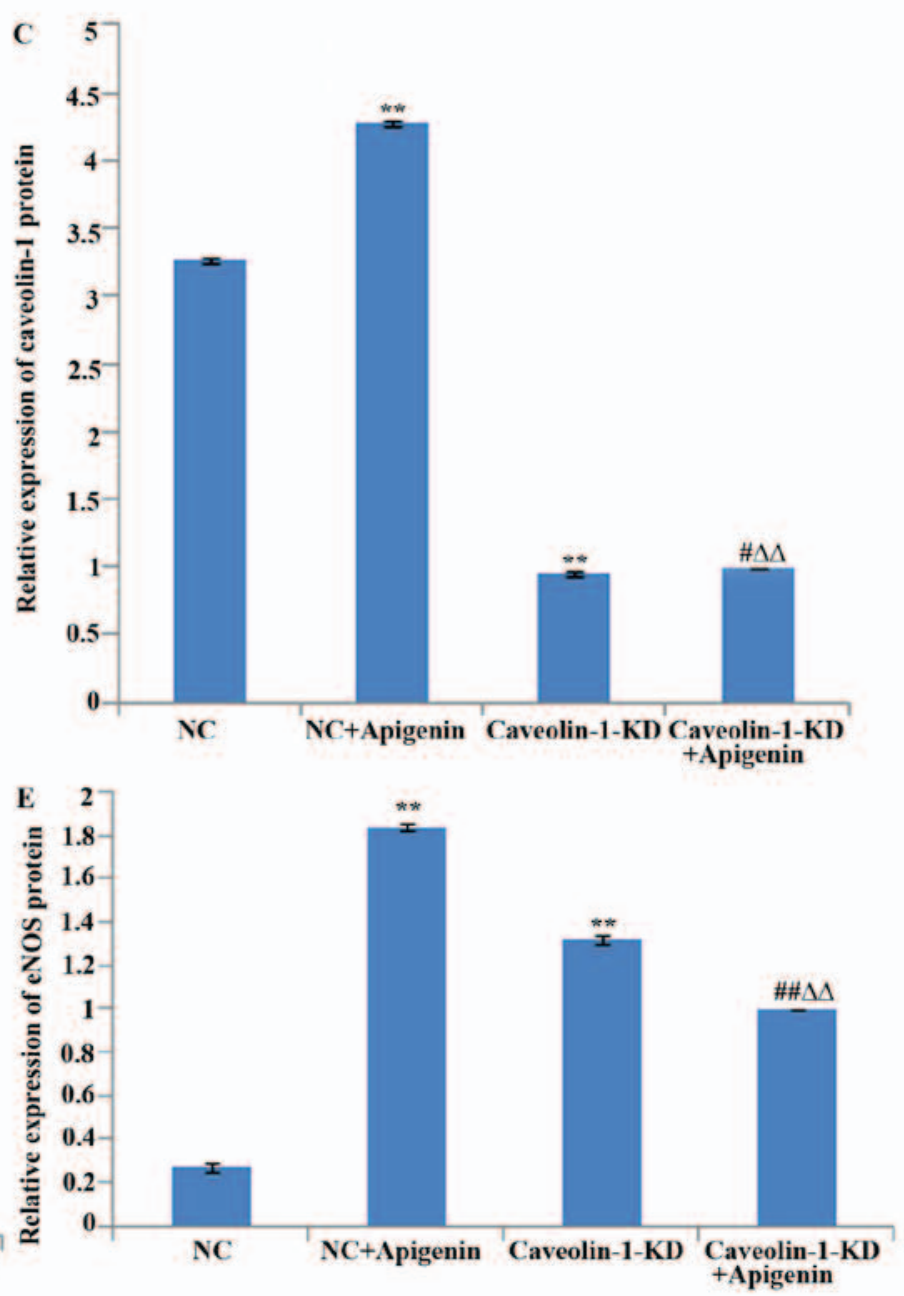

Figure 7. Effects of apigenin and caveolin-1 silencing on caveolin-1, vascular endothelial growth factor (VEGF) and endothelial nitric oxide synthase (eNOS) levels in human umbilical vein endothelial cells (HUVECs) after hypoxia-reoxygenation (HR). Cells were analyzed after hypoxia for $6 \mathrm{~h}$ and reoxygenation for $24 \mathrm{~h}$ under three conditions: normal conditions (NC group), transfection of caveolin-1 short interfering RNA (siRNA) (caveolin-1-KD group), and treatment with apigenin (NC + apigenin and caveolin-1-KD + apigenin groups). (A) RT-PCR analysis of caveolin-1 in HUVECs. Caveolin-1 silencing affected caveolin-1 mRNA expression. Apigenin did not recover caveolin-1 mRNA expression after caveolin-1 silencing. (B) Western blot analysis of protein levels of caveolin-1, VEGF and eNOS in HUVECs. (C) Apigenin promoted caveolin-1 protein expression after HR. Caveolin-1 silencing affected caveolin-1 protein expression. Apigenin restored caveolin-1 protein expression after caveolin-1 silencing. (D) Apigenin promoted VEGF expression after HR. Caveolin-1 silencing did not affect the expression of VEGF. Apigenin did not increase VEGF expression after HUVECs were transfected with caveolin-1 siRNA. (E) Apigenin promoted eNOS expression after HR. Caveolin-1 silencing downregulated eNOS expression. Apigenin did not upregulate eNOS expression after caveolin-1 silencing. All values are presented as the mean \pm SEM of three experiments $(\mathrm{n}=3)$. ${ }^{* *} \mathrm{P}<0.01$ vs. NC group; ${ }^{\#} \mathrm{P}<0.05$ vs. caveolin-1-KD group; ${ }^{\# \#} \mathrm{P}<0.01$ vs. caveolin-1-KD group; ${ }^{\Delta \Delta} \mathrm{P}<0.01$ vs. $\mathrm{NC}+$ apigenin group. 
In vitro angiogenesis can be evaluated by migration and tube formation assays. As expected, our results showed that apigenin promoted cell viability, migration, and tube formation. However, this stimulatory effect was significantly inhibited by caveolin-1 siRNA, suggesting that caveolin-1 induction by apigenin is important to control angiogenesis. Apigenin could not recover tube formation, but increased the migration and proliferation of HUVECs, which were inhibited by caveolin-1 siRNA.

The underlying mechanisms of the angiogenic effect of apigenin remain unclear. In the present study, we demonstrated for the first time that apigenin promotes angiogenesis via caveolin-1 in HUVECs after HR. As shown previously, caveolin-1 is downregulated in the core and penumbra in ischemic brains $(31,32)$. Our results showed that HR decreased caveolin-1 expression in HUVECs. We also found that apigenin treatment restored high caveolin-1 protein levels. Although the protein level was increased in cells treated with apigenin and exposed to HR, transcription of caveolin-1 was unaltered, suggesting that apigenin may affect post-translational processes of caveolin-1 expression.

We also investigated the involvement of apigenin in promotion of angiogenesis through VEGF and eNOS pathways. VEGF and eNOS-derived NO are important regulators of angiogenesis. However, the underlying mechanism regarding the modulation of caveolin-1 in the secretion of VEGF and eNOS remain ambiguous. VEGF is an angiogenesis accelerator, and caveolin-1 may play an important role in angiogenesis induced by VEGF (33). It is well established that VEGF is induced when tissue is subjected to hypoxic and ischemic attack. VEGF stimulates the proliferation and migration of vascular endothelial cells and increases the permeability of vessels as well as the differentiation of endothelial cells into capillary tubes $(34,35)$. In this study, VEGF expression was increased in HUVECs after $\mathrm{HR}$, and apigenin upregulated VEGF expression, indicating that apigenin may directly activate angiogenic signaling pathways. Intriguingly, after treatment of endothelial cells with caveolin-1 siRNA, the expression of VEGF protein did not significantly change. This result may be attributed to the association of VEGF with other molecules in the cells. It has been demonstrated that VEGF enhances the expression of eNOS in native and cultured endothelial cells, an effect that may be important in the process of VEGF-induced angiogenesis. VEGF-induced vascular permeability and angiogenesis were found to be markedly reduced in eNOS-deficient mice (36). In this study, the increased expression of eNOS may have upregulated VEGF expression. Therefore, further studies are needed to confirm the involvement of the eNOS-VEGF pathway in the angiogenic effect of apigenin. However, apigenin-increased VEGF protein expression was inhibited by caveolin-1 silencing. Therefore, the increase in angiogenesis by apigenin may be partly mediated via caveolin-1 regulating VEGF expression.

Several lines of evidence have shown upregulation of eNOS activation by hypoxia (37). This study produced the same results. The only direct protein-protein interaction demonstrated in vivo between caveolin-1 and a non-homologous protein is with eNOS. Studies have demonstrated that caveolin-1 functions as an endogenous negative regulator of eNOS activity (38-41). Binding of eNOS to caveolin-1 often leads to its inactivation (42). Our results demonstrated that apigenin promoted eNOS protein expression in HUVECs after HR, suggesting the involvement of eNOS in angiogenesis after HR injury. Furthermore, our data showed an increase in the protein expression of eNOS after caveolin-1 silencing, which is supported by a previous study (43). They showed that caveolin-1 deficiency induced the activation of eNOS and the generation of NO. It is important that eNOS is downregulated when cells are treated with apigenin. We believe that upon treatment with apigenin after caveolin-1 silencing, caveolin-1 was upregulated by apigenin, which bound to eNOS and inhibited its activity. Activation of eNOS promoted caveolin-1 phosphorylation and eNOS/caveolin-1 binding, creating an inhibitive feedback loop for eNOS (44). Nevertheless, our data suggest that caveolin-1 modulated angiogenesis of HUVECs after HR in part through its negative regulation of eNOS activity. Therefore, apigenin may promote angiogenesis through the caveolin-1/eNOS pathway.

Although apigenin treatment enhanced angiogenesis of HUVECs via caveolin-1 after HR, other studies showed that apigenin is a natural chemopreventive agent with clear antiangiogenic effects in tumors $(45,46)$. Tong et al $(47)$ showed that $50 \mu \mathrm{M}$ apigenin affected ultraviolet B-induced cutaneous proliferation and angiogenesis. In the present study, we examined the viability of HUVECs treated with various concentrations of apigenin after HR. The results showed that $\geq 50 \mu \mathrm{M}$ apigenin had a cytotoxic effect, but had protective effects on cells at lower concentrations. Therefore, we speculate that the effects were dose-dependent in these assays. Furthermore, the effects of apigenin may be different in various tissues and cell types.

Taken together, our findings suggest that apigenin may be a novel agent to promote angiogenesis after HR injury. However, there are several important caveats to consider. Although our data provide cellular and pharmacological proof of principle for apigenin in endothelial cell angiogenesis, in vitro endothelial cell cultures may not recapitulate similar changes occurring in primary cultures or stroke models in vivo. Therefore, the proangiogenic utility of apigenin as a potential stroke recovery therapy should be explored in future studies.

\section{Acknowledgements}

This study was supported by the Medical Research Project of Zhejiang Province (2016KYB201), and the Wenzhou Municipal Science and Technology Bureau Project Funding (Y20150017), and the Key Construction Disciplines (Children's Rehabilitation) at the Second Affiliated Hospital of Wenzhou Medical University.

\section{References}

1. Semenza GL: Vasculogenesis, angiogenesis, and arteriogenesis: Mechanisms of blood vessel formation and remodeling. J Cell Biochem 102: 840-847, 2007.

2. Carmeliet P: Mechanisms of angiogenesis and arteriogenesis. Nat Med 6: 389-395, 2000.

3. Kofler S, Nickel T and Weis M: Role of cytokines in cardiovascular diseases: A focus on endothelial responses to inflammation. Clin Sci (Lond) 108: 205-213, 2005.

4. Papetti M and Herman IM: Mechanisms of normal and tumorderived angiogenesis. Am J Physiol Cell Physiol 282: C947-C970, 2002.

5. Shergill U, Das A, Langer D, Adluri R, Maulik N and Shah VH: Inhibition of VEGF- and NO-dependent angiogenesis does not impair liver regeneration. Am J Physiol Regul Integr Comp Physiol 298: R1279-R1287, 2010. 
6. Yoshida D, Akahoshi T, Kawanaka H, Yamaguchi S, Kinjo N, Taketomi A, Tomikawa M, Shirabe K, Maehara Y and Hashizume M: Roles of vascular endothelial growth factor and endothelial nitric oxide synthase during revascularization and regeneration after partial hepatectomy in a rat model. Surg Today 41: 1622-1629, 2011.

7. Fan TP, Yeh JC, Leung KW, Yue PY and Wong RN: Angiogenesis: From plants to blood vessels. Trends Pharmacol Sci 27: 297-309, 2006.

8. Rahman A and Swärd K: The role of caveolin-1 in cardiovascular regulation. Acta Physiol (Oxf) 195: 231-245, 2009.

9. Sowa G: Caveolae, caveolins, cavins, and endothelial cell function: New insights. Front Physiol 2: 120, 2012

10. Mundy DI, Machleidt T, Ying YS, Anderson RG and Bloom GS Dual control of caveolar membrane traffic by microtubules and the actin cytoskeleton. J Cell Sci 115: 4327-4339, 2002.

11. Navarro A, Anand-Apte B and Parat MO: A role for caveolae in cell migration. FASEB J 18: 1801-1811, 2004.

12. Gao Y, Zhao Y, Pan J, Yang L, Huang T, Feng X, Li C, Liang S, Zhou D, Liu C, et al: Treadmill exercise promotes angiogenesis in the ischemic penumbra of rat brains through caveolin-1/VEGF signaling pathways. Brain Res 1585: 83-90, 2014.

13. Liu J, Wang XB, Park DS and Lisanti MP: Caveolin-1 expression enhances endothelial capillary tubule formation. J Biol Chem 277: 10661-10668, 2002.

14. Frank PG, Woodman SE, Park DS and Lisanti MP: Caveolin, caveolae, and endothelial cell function. Arterioscler Thromb Vasc Biol 23: 1161-1168, 2003.

15. Gratton JP, Bernatchez P and Sessa WC: Caveolae and caveolins in the cardiovascular system. Circ Res 94: 1408-1417, 2004.

16. Fleming I and Busse R: Molecular mechanisms involved in the regulation of the endothelial nitric oxide synthase. Am J Physiol Regul Integr Comp Physiol 284: R1-R12, 2003.

17. Ju H, Zou R, Venema VJ and Venema RC: Direct interaction of endothelial nitric-oxide synthase and caveolin-1 inhibits synthase activity. J Biol Chem 272: 18522-18525, 1997.

18. Wang QQ, Cheng N, Yi WB, Peng SM and Zou XQ: Synthesis, nitric oxide release, and $\alpha$-glucosidase inhibition of nitric oxide donating apigenin and chrysin derivatives. Bioorg Med Chem 22: $1515-1521,2014$

19. Woodman OL and Chan EC: Vascular and anti-oxidant actions of flavonols and flavones. Clin Exp Pharmacol Physiol 31: 786-790, 2004.

20. Olszanecki R, Gebska A, Kozlovski VI and Gryglewski RJ Flavonoids and nitric oxide synthase. J Physiol Pharmacol 53: 571-584, 2002

21. Guerrero JA, Lozano ML, Castillo J, Benavente-García O, Vicente V and Rivera J: Flavonoids inhibit platelet function through binding to the thromboxane A2 receptor. J Thromb Haemost 3: 369-376, 2005.

22. Liu LZ, Fang J, Zhou Q, Hu X, Shi X and Jiang BH: Apigenin inhibits expression of vascular endothelial growth factor and angiogenesis in human lung cancer cells: Implication of chemoprevention of lung cancer. Mol Pharmacol 68: 635-643, 2005

23. Ansó E, Zuazo A, Irigoyen M, Urdaci MC, Rouzaut A and Martínez-Irujo JJ: Flavonoids inhibit hypoxia-induced vascular endothelial growth factor expression by a HIF-1 independent mechanism. Biochem Pharmacol 79: 1600-1609, 2010.

24. Li XM, Niu WZ and Chen X: Effect of apigenin on expression of VEGF in cerebral ischemia and reperfusion rats. Chin Pathophysiol 26: 2473-2477, 2010.

25. Niu WZ, Li XM, Wang G, Han X and Chen X: Effects of apigenin on caveolin -1 expression of focal cerebral ischemia-reperfusion in rats. Chin Tradit Herbal Drugs 41: 1658-1662, 2010.

26. Li Q, Wu J, Wei P, Xu Y, Zhuo C, Wang Y, Li D and Cai S: Overexpression of forkhead Box $\mathrm{C} 2$ promotes tumor metastasis and indicates poor prognosis in colon cancer via regulating epithelialmesenchymal transition. Am J Cancer Res 5: 2022-2034, 2015.

27. Taylor AC, Seltz LM, Yates PA and Peirce SM: Chronic whole-body hypoxia induces intussusceptive angiogenesis and microvascular remodeling in the mouse retina. Microvasc Res 79: 93-101, 2010

28. Lopez-Jornet P, Camacho-Alonso F, Gómez-Garcia F, Molina Miñano F, Cañas X, Serafín A, Castillo J and VicenteOrtega V: Effects of potassium apigenin and verbena extract on the wound healing process of SKH-1 mouse skin. Int Wound J 11: 489-495, 2014
29. Liu P, Rudick M and Anderson RG: Multiple functions of caveolin-1. J Biol Chem 277: 41295-41298, 2002.

30. Chidlow JH Jr and Sessa WC: Caveolae, caveolins, and cavins Complex control of cellular signalling and inflammation. Cardiovasc Res 86: 219-225, 2010.

31. Shen J, Ma S, Chan P, Lee W, Fung PC, Cheung RT, Tong Y and Liu KJ: Nitric oxide down-regulates caveolin-1 expression in rat brains during focal cerebral ischemia and reperfusion injury. J Neurochem 96: 1078-1089, 2006

32. Li Y, Luo J, Lau WM, Zheng G, Fu S, Wang TT, Zeng HP, So KF, Chung SK, Tong Y, et al: Caveolin-1 plays a crucial role in inhibiting neuronal differentiation of neural stem/progenitor cells via VEGF signaling-dependent pathway. PLoS One 6: e22901, 2011

33. Tahir SA, Park S and Thompson TC: Caveolin-1 regulates VEGF-stimulated angiogenic activities in prostate cancer and endothelial cells. Cancer Biol Ther 8: 2286-2296, 2009.

34. Roy S and Sen CK: miRNA in wound inflammation and angiogenesis. Microcirculation 19: 224-232, 2012.

35. Peng W, Yu Y, Li T, Zhu Y and Chen H: The effects of small interfering RNA-targeting tissue factor on an in vitro model of neovascularization. Mol Vis 19: 1296-1303, 2013.

36. Fukumura D, Gohongi T, Kadambi A, Izumi Y, Ang J, Yun CO, Buerk DG, Huang PL and Jain RK: Predominant role of endothelial nitric oxide synthase in vascular endothelial growth factor-induced angiogenesis and vascular permeability. Proc Nat Acad Sci USA 98: 2604-2609, 2001

37. Qing M, Görlach A, Schumacher K, Wöltje M, VazquezJimenez JF, Hess J and Seghaye MC: The hypoxia-inducible factor HIF-1 promotes intramyocardial expression of VEGF in infants with congenital cardiac defects. Basic Res Cardiol 102: 224-232, 2007.

38. Drab M, Verkade P, Elger M, Kasper M, Lohn M, Lauterbach B, Menne J, Lindschau C, Mende F, Luft FC, et al: Loss of caveolae, vascular dysfunction, and pulmonary defects in caveolin-1 gene-disrupted mice. Science 293: 2449-2452, 2001.

39. Razani B, Engelman JA, Wang XB, Schubert W, Zhang XL, Marks CB, Macaluso F, Russell RG, Li M, Pestell RG, et al: Caveolin-1 null mice are viable but show evidence of hyperproliferative and vascular abnormalities. J Biol Chem 276: 38121-38138, 2001

40. Zhao YY, Liu Y, Stan RV, Fan L, Gu Y, Dalton N, Chu PH, Peterson K, Ross J Jr and Chien KR: Defects in caveolin-1 cause dilated cardiomyopathy and pulmonary hypertension in knockout mice. Proc Natl Acad Sci USA 99: 11375-11380, 2002

41. Maniatis NA, Shinin V, Schraufnagel DE, Okada S, Vogel SM, Malik AB and Minshall RD: Increased pulmonary vascular resistance and defective pulmonary artery filling in caveolin- $1^{-1}$ mice. Am J Physiol Lung Cell Mol Physiol 294: L865-L873, 2008.

42. Mehta D and Malik AB: Signaling mechanisms regulating endothelial permeability. Physiol Rev 86: 279-367, 2006.

43. Siddiqui MR, Komarova YA, Vogel SM, Gao X, Bonini MG, Rajasingh J, Zhao YY, Brovkovych V and Malik AB: Caveolin1-eNOS signaling promotes p190RhoGAP-A nitration and endothelial permeability. J Cell Biol 193: 841-850, 2011.

44. Chen Z, Bakhshi FR, Shajahan AN, Sharma T, Mao M, Trane A, Bernatchez P, van Nieuw Amerongen GP, Bonini MG, Skidgel RA, et al: Nitric oxide-dependent Src activation and resultant caveolin-1 phosphorylation promote eNOS/caveolin-1 binding and eNOS inhibition. Mol Biol Cell 23: 1388-1398, 2012

45. Tong X and Pelling JC: Targeting the PI3K/Akt/mTOR axis by apigenin for cancer prevention. Anticancer Agents Med Chem 13: 971-978, 2013

46. Fang J, Zhou Q, Liu LZ, Xia C, Hu X, Shi X and Jiang BH: Apigenin inhibits tumor angiogenesis through decreasing HIF-1alpha and VEGF expression. Carcinogenesis 28: 858-864, 2007.

47. Tong X, Mirzoeva S, Veliceasa D, Bridgeman BB, Fitchev P, Cornwell ML, Crawford SE, Pelling JC and Volpert OV: Chemopreventive apigenin controls UVB-induced cutaneous proliferation and angiogenesis through $\mathrm{HuR}$ and thrombospondin-1. Oncotarget 5: 11413-11427, 2014.

This work is licensed under a Creative Commons Attribution-NonCommercial-NoDerivatives 4.0 International (CC BY-NC-ND 4.0) License. 